\title{
Compositionality, Iconicity, and Perceptual Nonconceptualism
}

\author{
Josefa Toribio ${ }^{1}$
}

\begin{abstract}
.
This paper concerns the role of the structural properties of representations in determining the nature of their content. I take as a starting point Fodor's (2007) and Heck's (2007) recent arguments making the iconic structure of perceptual representations essential in establishing their content as content of a different (nonconceptual) kind. I argue that the prima facie state / content error this strategy seems to display is nothing but a case of 'state/content error error', i.e., the mistake of considering that the properties that characterize the type of content certain representations have are indeed independent of their structural properties. I also consider another objection to the general strategy, namely that it falls short of showing that the nonconceptual content of perceptual experiences thus established is the kind of content that figures in true explanations of intentional behavior. I concede this point in respect of Fodor's version of the strategy, while denying that it has any bearing on Heck's approach. The success of this objection in Heck's case ultimately depends, I argue, upon an unjustified commitment to a certain empirically suspect model of perception.
\end{abstract}

\section{Introduction}

Neo-Fregean philosophers follow Evans in defending the idea that genuine instances of thinking are necessarily subject to the principle of compositionality that he dubbed 'the Generality Constraint' (GC henceforth) (see e.g., Davies, 1992; McDowell, 1994; Peacocke,

\footnotetext{
${ }^{1}$ Josefa Toribio is an ICREA Research Professor at the UAB, Department of Philosophy, Facultat de Filosofia i Lletres. Building B, 08193 Bellaterra, Barcelona, Spain. Email: jtoribio@icrea.cat
} 
1992, 2001). According to (a version of) GC (Evans, 1982, p.104): "if a subject can be credited with the thought that $a$ is $F$, then he must have the conceptual resources for entertaining the thought that $a$ is $G$, for every property of being $G$ of which he has a conception." A subject can thus be credited with the thought that Mary is tall, only if she can also think of Mary as having some other property such as e.g. being intelligent - a property for which the subject has a concept. In a slightly different version of GC, Evans argues that a subject can be credited with the thought that a particular object has a property, only if the subject can also think of other objects as having this very same property. The attribution to a subject of a contentful state of the form $a$ is $F$ thus commits us to the idea that that subject should also be able to represent $a$ as $G$ and $b$ as $F$ (Evans, 1982, p. 104, ft. 21).

Cognitive atomists, like Fodor, being perhaps more empirically minded, deny that GC is necessarily true. They think that it is just highly unlikely, although perhaps not impossible, that there may be creatures who could think that Mary is intelligent and John is tall, but not that Mary is tall and John is intelligent (Fodor, 1987, pp. 148-153; Fodor and Pylyshyn, 1988). They view GC as a contingent truth about thought. For Fodor, all actual instances of thinking have a language-like structure. Fodor appeals to the compositional structure of conceptual representations in an inference to the best explanation of the undeniable systematicity and productivity of thought and language. Hence his commitment to a language of thought hypothesis.

Both neo-Fregeans and Concept Atomists, despite their different approach to GC and to concepts, thus agree that the content of the representations involved in genuine instances of thinking is conceptual because such representations have the kind of compositional structure that supports the generalizations GC makes explicit. It is against the background of this general picture of conceptual content that the - essentially contrastive- notion of nonconceptual content is usually presented.

The notion of nonconceptual content becomes central, not only, but noticeably, in debating the nature of the content of the representations involved in personal-level perceptual experience. Here neo-Fregeans split into two irreconcilable camps: conceptualist and 
nonconceptualist. Perceptual conceptualists (e.g. McDowell, 1994; Brewer, 1999, 2005) defend the view that the way a subject represents the world in experience can be fully specified by using concepts she possesses. Nonconceptualists (e.g. Peacocke, 1992; Heck, 2000) maintain that there are ways of representing the world that do not reflect the concepts a creature possesses. Although, for the conceptualist, the content of perceptual experiences is conceptual and hence perception, like thought, is subject to GC, the constraint has not played, so far, a significant role in the dialectics of this traditional version of the debate, i.e., the tradition that begins with Evans and that has McDowell and Peacocke as main representatives of the, respectively, conceptualist and nonconceptualist camps. ${ }^{i}$ This may not seem surprising. On the one hand, the perceptual conceptualist's motivation for claiming that the content of perceptual experiences is conceptual has never been to show that perception, like thought and language, is productive and systematic. On the other hand, the most important arguments on the nonconceptualist side of the debate have also revolved around issues other than GC's failure to govern perception, issues such as the fine-grained character of perceptual experience, the putative continuity in the way creatures with different conceptual repertoires represent the world in their perceptual experiences, the need for a noncircular account of perceptual concept possession and acquisition (Peacocke 1992, 2001), the correct explanation of sensorimotor behavior and know-how (Cussins, 1992) and the need to comprehend the mental life of pre-linguistic children and non-linguistic animals (Bermúdez, 1998, 2003). ${ }^{\mathrm{ii}}$

These arguments have always been controversial, but they have recently been criticized using a new tactic. It has been pointed out that perceptual nonconceptualism admits of two different interpretations (see e.g. Crowther, 2006; Heck, 2000; Laurier, 2004; Speaks, 2005; Tye, 2006). On the first one, nonconceptualism is a thesis about the kind of content perceptual states, as opposed to e.g. beliefs, have. ${ }^{\text {iii }}$ Being nonconceptual is here depicted as a property of the content of perceptual states. On the second interpretation, being nonconceptual is a property of perceptual states, not of their content. Perceptual nonconceptualism, on this latter view, is a thesis about a particular type of representational state, i.e., a particular type of representations. Being nonconceptual is thus the property that a mental state has if the subject that instantiates such a state need not possess the concepts 
involved in a correct characterization of its content. It has become standard to refer to these two interpretations of perceptual nonconceptualism as, respectively, the 'content' and the 'state' view (Heck, 2000). iv Most proponents of this distinction have used it in an attempt to show that the many of the arguments in favor of perceptual nonconceptualism succeed only in establishing the truth of the state view, but leave the - stronger - content view unsupported. The new tactic against these arguments thus consists in complaining that they conflate questions about the properties of perceptual states with questions about the properties of their content.

The contemporary partnership between neo-Fregean nonconceptualists (such as Heck, 2007) and Concept Atomists (such as Fodor, 2007) should strike a dissonant cord against the backdrop of the criticisms arising from this state / content distinction. Fodor and Heck join forces to argue that discursive representations have, while perceptual representations lack, a canonical decomposition. Instead, perceptual representations have an iconic structure and - they argue - the possession of such a different structure is so cognitively relevant that the content of perceptual representations should be considered content of a different (nonconceptual) kind. If successful, this dialectical move would not only provide an argument in favor of the - stronger - content view of perceptual nonconceptualism, but also, and importantly, it would actually undermine the very distinction between the state and content view, as it would show that questions about mental states' structure can be relevant for solving issues about mental states' content. The dialectical move is also interesting because it turns the issue of the existence of nonconceptual content into an empirical one. If nonconceptual content is the content of iconic representations, then, if experimental psychology provides good examples of iconic representations, as it seems it does, we would have not just an argument but actually evidence in favor of the existence of nonconceptual content - a challenge for those who argue against the intelligibility of such a notion on a priori grounds (e.g. McDowell, 1994).

This paper concerns the role of the structural properties of perceptual states in determining the (nonconceptual) nature of their content. I take Fodor's (2007) and Heck's (2007) recent arguments as a starting point. I examine their plausibility in light of the 
distinction between state and content (non)conceptualism, since, at least prima facie, the structural properties that states of a given type have don't tell us anything about their content, and thus Fodor's and Heck's dialectical move could be considered a clear case of state / content error. I argue that this worry is nothing but an instance of a 'state / content error error'v -i.e., the error of considering that, once the approach to mental content is made from the perspective of psychological explanation, the properties that characterize the type of content certain states have are independent of their structural properties. The shift in strategy should be welcomed as a way of clarifying what is really at issue in the perceptual (non)conceptualism debate, but also, and more generally, for bringing to the fore the issue of how - on a certain understanding of mental content - the structural properties of the representations underlying certain cognitive states become crucial for explaining their psychological profile. In this vein, I also consider another objection to the general strategy, namely that it falls short of showing that the nonconceptual content of perceptual representations thus established is the kind of content that figures in true explanations of intentional behavior (see e.g. Poston, 2007). I concede the point in respect of Fodor's version of the strategy, while denying that it has any bearing on Heck's approach.

\section{Iconic vs. discursive modes of representation.}

It is widely held that entertaining the thought that e.g. Mary is intelligent requires representing Mary as an object that falls under the concept intelligent —as well as being able to represent other objects as also falling under the same concept and being able to represent the object Mary falling under some other concept. Discursive representations thus exhibit the type of compositional structure captured by GC and are considered paradigms of representations whose content is conceptual. The philosophical slogan that conceptual content is content subject to GC should be understood as a slightly inaccurate expression of this idea. Slightly inaccurate because it's thinkers' cognitive processes that are governed by $\mathrm{GC}$ and hence a more neutral way of approaching the kind of generalizations that GC makes explicit is to talk about the compositionality of mental representations ${ }^{\mathrm{vi}}$. A representation is then compositional if and only if its content and syntactic structure is determined by the 
content and the syntactic structure of its constituents. But, as Fodor (2007, p. 108) reminds us, "not every part of a discursive representation is ipso facto one of its constituents." To use his example, take a sentence such as 'John loves Mary'. The syntactic structure of this sentence is made explicit in (1).

(1) $(\text { John })_{\mathrm{NP}}\left((\text { loves })_{\mathrm{V}}\left((\text { Mary })_{\mathrm{NP}}\right)_{\mathrm{VP}}\right)_{\mathrm{S}}$

'John', 'Mary', and 'loves Mary’ are constituents of 'John loves Mary’, but it would be a mistake to think that 'John loves' or 'John ... Mary' also are. 'John loves' and 'John ... Mary' are not parts that could figure in the canonical decomposition captured by (1) and since "[ $\mathrm{t}]$ he constituents of a discursive representation are those of its parts that are recognized by its canonical decomposition" (Fodor, 2007, p. 108), 'John loves' and 'John ... Mary' are not constituents of 'John loves Mary'. They are not constituents of 'John loves Mary' because they do not have a semantic interpretation of their own that contributes to the semantic interpretation of the sentence — even if 'John' and 'Mary', as lexical primitives, do.

Some representations, Fodor argues, do not have a canonical decomposition at all. It is not just that some of their parts are constituents and some aren't. It's just that some representations do not have any constituents thus understood. They are iconic. Pictures are paradigms of representations that do not admit a canonical decomposition and hence do not have constituents. Pictures are paradigms of iconic representation. Pictures do have structure and they thus have parts, but each part contributes in the same way to the interpretation of the picture. If talking about compositionality makes any sense here, it is only in the following diluted sense captured by Fodor's Picture Principle: "If $\mathrm{P}$ is a picture of $\mathrm{X}$, then parts of $\mathrm{P}$ are pictures of parts of X" (Fodor, 2007, p. 108).

As iconic representations, pictures have all kind of properties that discursive representations lack. Although they are semantically evaluable, they do not have logical form - as the logical form of a representation is determined by its constituents and pictures do not have constituents. There isn't e.g. anything like the negation of a picture or the disjunction of two pictures. Since they do not have logical form, Fodor argues, there are no principles of 
individuation that could be applied to what they depict. They do represent, but they do not represent as: "a picture may show three giraffes in the veldt, but it likewise shows: a family of giraffes; and an odd number of Granny's favorite creatures; and a number of Granny's favorite odd creatures; and a piece of veldt that is inhabited by any or all of these" (Fodor, 2007, p. 110). Since to represent as is characteristic of conceptualized representations, iconic representations, which do not represent as have, Fodor assumes, a different kind of content: one worth calling 'non-conceptual content.'

There are, to be sure, several different questions here. I'll use three of them to guide the discussion in the rest of the paper. The first, empirical, question is whether or not there are any mental representations that are iconic in the sense just explained. It's one of the merits of Fodor's paper (2007, pp. 112-113) to convince us that the literature in the psychology of perception is full of cases that seem to suggest that there are indeed mental representations that exhibit the properties captured by his idea of iconicity. In particular, some of the earliest processes through which visual information goes seem to operate on representations that do not individuate the items they represent. Fodor reminds us of Sperling's experiments (1960), in which subjects are exposed to a $3 \times 4$ grid of alphanumeric characters for 50 milliseconds. After a blank delay of up to $500 \mathrm{msec}$., subjects insist that the can visualize all or almost all the characters they have seen, but are usually able to report only up to four of them. Nonetheless, Sperling showed that when prompted by differently pitched tones for each row, played immediately after the $4 \times 3$ display has been turned off, subjects are able to retrieve all or almost all the alphanumeric characters in any given row, i.e., subjects are able to report the top row of the grid if prompted by the high pitched tone, the bottom row if prompted by the low pitched tone and the middle if the medium pitched tone was produced. ${ }^{\text {vii }}$ These results suggest that the subjects do have conscious access to all the visual information, but that such information, as it becomes conceptualized, is then subject to limitations imposed by (probably) short-term memory.

It's not just Fodor who relies on experimental psychology to provide evidence for the existence of iconic mental representations. Cognitive maps - the kind of mental representations we make of our environment in order to find our way around - become the 
central case in Heck's defense of the iconicity of certain mental representations (2007, pp. 125-128). Cognitive maps are presented as a clear instance of action-oriented mental representations of spatial information that do not have a canonical decomposition. Topographic features in cognitive maps are often defined relative to each other, and relative to the map, in an iconic fashion, so there is no canonical way of decomposing the maps' interpretable parts. One of the consequences of representing spatial information in this way, one very much in harmony with Fodor's idea of iconic representations lacking any kind of logical form, is that the information in cognitive maps is not closed under Boolean operations - again, there isn't anything like the negation of my cognitive map of central Edinburgh.

Cognitive maps can and do enter into processes of rationalization. That seems difficult to deny. We form beliefs about where things are based on the cognitive maps we have of our environments and behave in ways that can be accounted for by our relying on having represented spatial information in that particular way. However, cognitive maps, Heck argues, fail to meet the following two empirical conditions characteristic of states with conceptual content. First, the states must be structured in such a way as to support the generalizations made explicit by GC. Second, and importantly, the assumption that conceptual states are thus structured ought to provide the basis for an explanation of the GC's satisfaction itself (Heck, 2007, p. 123). Heck argues that cognitive maps either do not support the sorts of generalizations required by GC or the fact that such generalizations hold cannot be explained in terms of the cognitive maps' structural features. He then contends that perceptual experiences are like cognitive maps in that respect. The content of perceptual experiences is - he concludes — of a different kind, i.e., nonconceptual.

If Fodor and Heck are both right, not only are there iconic mental representations so we have an affirmative answer to our first, empirical, question — but the representations involved in perceptual experiences fall under such a category. This being the case, the second most relevant question clearly is whether the iconicity of perceptual representations could be brought to bear on the issue of the nonconceptual nature of their content. I examine this issue at length in the next two sections. Also in Section 4 and in Section 5, I address the third and final question of whether the notion of nonconceptual content that comes out of this 
strategy is a notion that applies to the content of the subject's experience and hence whether it can appear in true explanations of the subject's intentional behavior. I call this 'the subpersonal worry' — a recurrent worry in e.g. Poston (2007). In Section 6 I offer some concluding remarks.

\section{Representations and their content.}

The question of whether the iconic structure of perceptual representations determines the (nonconceptual) nature of their content is a particular case of a more general issue, namely, whether the properties of mental states tell us anything about the kind of content they have. As I said in the Introduction, the issue is particularly pressing, as the fact that certain states are structured (or structured in a particular way) need not show that their contents are too, and vice-versa. The dialectical move from statestructure to content-nature may thus appear to be a version of the vehicle / content confusion: the confusion of thinking that the representational properties of a certain type of states reflect their causally relevant structural properties. In fact, the recent distinction between 'state' and 'content' interpretations of perceptual nonconceptualism can be viewed as a reminder of the dangers of ignoring the vehicle / content distinction. But before I bring the discussion under that rubric (in next section), there is a question that I'd like to address here first.

It is fairly standard, at least in the context of discussions about the content of perception, to find conceptual content characterized as content that is structured so as to satisfy the generalizations supported by GC or, more frequently, content that is subject to GC. The move from state-structure to content-nature thus seems to be granted in the case of thought - and not just for those involved in the traditional perceptual (non)conceptualism debate, i.e., for the neo-Fregeans. As mentioned earlier, Concept Atomists also take the compositional structure captured by GC to determine the conceptual nature of thought content. So, if there are indeed good reasons to grant this dialectical move in the case of conceptual content, the claim that nonconceptual content 
is content so (canonically un)structured so as to fail to satisfy the generalizations supported by GC shouldn't be regarded as prima facie theoretically suspicious. So, are there good independently motivated reasons warranting the neo-Fregeans' and Concept Atomists' move from considerations about state-structure to considerations about content-nature in the case of conceptual content?

I think there are. Despite holding unmistakably opposite views on concepts and despite being motivated by totally different considerations (more about this shortly), what explains why neo-Fregeans and Concept Atomists join forces to defend the relevance of GC for characterizing the notion of conceptual content is that both seek a cognitively relevant notion of mental content, i.e., a notion of content that links content individuation and content attribution to true psychological explanations of intentional behavior. And one plausible way of making content psychologically sensitive is to appeal to the causally explanatory structural features of the mental representations with such content - the kind of structural features that $\mathrm{GC}$ arguably makes explicit. Both neo-Fregeans and Atomists, as opposed to e.g. those who hold a pleonastic view of concepts (Byrne, 2005) or those who characterized content in terms of a function of possible worlds to truth values (e.g. Lewis, 1973; Stalnaker, 1968) thus consider it a desideratum of any theory of content to give an account of how the content of mental representations explains intentional behavior - with GC providing (either necessarily or contingently) just such an explanatory connection ${ }^{\text {iii. }}$. This (modally different) appeal to the structure that GC makes explicit allows both groups to deal with cases which have a different cognitive significance and hence, at least intuitively, a different content, yet the same reference - so-called Frege cases. It's just that, of course, whereas neo-Fregeans like Heck take the constituents of such structure to be individuated semantically and thus take Fregean senses as the constituents of thought, Concept Atomists like Fodor take the structure's constituents to be individuated syntactically: they are thus viewed as concrete mental representations - actual items syntactically tokened within the subject's cognitive architecture.

There are thus good, independently motivated reasons, for granting both neoFregeans and Concept Atomists their dialectical move from state-structure to content-nature 
in the case of conceptual content. I turn now to the issue of whether the difference between a syntactic and a semantic approach to GC might nevertheless have a significant consequence with regard to the plausibility of the same strategy in the case of nonconceptual content.

\section{State and content nonconceptualism.}

I suggested earlier that the plausibility of the state-structure to content-nature strategy in the case of nonconceptual content should go hand in hand with the plausibility of the same strategy with regard to conceptual content. I have now argued that there seem to be good reasons to think that the strategy works in the case of conceptual content. In the nonconceptual case, however, we face extra pressure in light of the recent distinction between 'state' and 'content' interpretations of perceptual nonconceptualism. Those who champion this distinction (e.g. Crowther, 2004; Speaks, 2005) argue that claims about concept possession and claims about compositionality are in fact logically independent, as shown by the prima facie coherence of the two following hybrid positions. On the one hand, it seems consistent to hold that, at least on a certain understanding of concept possession, perceptual experiences and beliefs have different kinds of content, but that, in both cases, the subject having the belief or undergoing the experience must have the concepts involved in a correct characterization of such content (let's call this thesis ' $\mathrm{SNCl}$ '). On the other hand, it also seems coherent to hold that the content of perceptual experiences and the content of beliefs are of the same kind, but that for a subject to undergo a perceptual experience, the subject need not possess the concepts involved in a correct characterization of its content while by contrast possession of the relevant concepts is indeed required in the case of belief (let's called this second hybrid position 'SCN2').

The argument for SNC1 can be summarized as follows: even if perceptual experiences and beliefs may be said to have different kinds of content in virtue of their different compositional structure, at least on a certain understanding of concept possession, it is the conceptual repertoire of the subject undergoing a perceptual experience that determines which contents are available to her as contents of her experience. Hence the content of 
perceptual experiences would be nonconceptual in a rather uninteresting, sub-personal, way (Crowther, 2004). It is here that what I call 'the sub-personal worry' appears for the first time. The worry, introduced as the third question for discussion at the end of Section 2, is that the (nonconceptual) content that non canonically decomposable perceptual representations have may not be content of the right kind, i.e., that it may not be the kind of content that captures the subject's own point of view.

Now, Fodor's position seems to fit SNC1's profile rather well. So, I'd like to show, first of all, that his nonconceptualism does succumb to the sub-personal worry. We have to remember that, for Fodor, concepts are individuated, not in terms of any of their epistemic properties, but in virtue of their being nomically locked onto properties in the subject's environment (1988). Concepts are mental representations and possessing a concept consists, on his view, in having a mental representation of what the concept is a concept of. Perceptual representations, by contrast, carry information about objects and properties in the world, but such representations, unlike conceptualized representations, do not individuate the objects and properties they represent, i.e., they do not represent anything as being a particular object or a particular property and hence have a different kind of (nonconceptual) content. Perceptual representations carry information in virtue of facts about reliable empirical connections between e.g. the subject's visual system and her environment, but it's only when such informational content enters into processes of thinking, and hence into processes that involve conceptualized representations, that it becomes the content of the subject's perceptual experience and hence it is the subject's conceptual repertoire that ultimately determines which contents become the contents of her experience. That seems to be precisely Fodor's interpretation of what's going on with the subjects in Sperling's experiment, when they can report only three of the letters they had been exposed to, but any three of them: "[s]o it appears there is a very short-term visual memory of which the capacity is, at a minimum, considerably greater than what $\mathrm{S}$ is able to read out of it. Apparently it is the cost of conceptualizing information in this memory, rather than the number of items that the memory is able to register, that bounds the subject's performance" (Fodor, 2007, p. 113, my emphasis). The fact that SNC1 seems to reflect Fodor's view on nonconceptual content so well may be considered a reason for the traditional neo-Fregean (non)conceptualist's to 
neglect it. Also, not surprisingly, a traditional conceptualist like McDowell would object that, on a view like SNC1, i.e., on Fodor's view “conceptual capacities... do not enter into determining the content with which one takes oneself to be presented, but serve only to account for one's access to that content, which is independently determined by the informational system" (McDowell, 1994, p. 64).

Let me move now to the second hybrid position, SNC2. The alleged logical independence of claims about representations and their content that SNC2 illustrates may be defended ${ }^{\text {ix }}$ when considering representations' relational properties, i.e., when it's the property of being related to a concept-possessing subject that it's taken to be decisive for determining the representations' kind of content. However such logical independence would become incoherent when, as in Heck's argument, the properties called upon are representations' intrinsic properties. This is why.

Heck's suggestion is, as we saw, that perceptual representations are like cognitive maps. Now, an essential feature of cognitive maps is that the spatial primitives, i.e., the landmarks, are always represented as a set of movements. But, this being the case, when we credit a subject with a spatial representation about an object $a$ at location $F$, this doesn't commit us to the idea that the subject can represent $a$ independently of $F$. Hence it doesn't commit us to the idea that the subject should also be able to represent $a$ at location $G$ or another object $b$ at location $F$. In other words, spatial representations do not seem to be subject to GC. If, as Heck claims, the representations involved in perceptual experiences are - like cognitive maps - essentially iconic and hence do not have a canonically decomposable structure, then we seem to have a strong argument in favor of taking the content of such representations to be of a genuinely different kind. Here, the iconicity of the representations makes it inconsistent to hold that the content of such representations is conceptual while the relationship between the subject undergoing a perceptual experience and the content of the representation involved in such an experience is nonconceptual. For this hybrid position to be consistent, the subject need not possess the concepts involved in a canonical characterization of the content of their perceptual representations. But the main 
feature of cognitive maps is precisely that there is no canonical characterization to begin with.

Furthermore, as a neo-Fregean, Heck (unlike Fodor) contends that an account of concepts is an account of concept possession. Possessing a concept is not to have a particular mental representation. Possessing a concept is an ability or set of complex abilities that the subject deploys whenever entertaining thoughts containing that concept. ${ }^{\mathrm{x}}$ Concepts are understood as ability-types, and, hence as the objective, non-psychological, abstract, entities that the Fregean gloss requires. At the same time, there is nothing more to the nature of those ability-types than their instantiation in the form of the set of abilities a subject exercises when she entertains thoughts containing that concept. On a characterization of concepts along this neo-Fregean line, SNC2 would thus become incoherent, as it would entail that a subject could exercise cognitive abilities she doesn't possess. On Heck's neo-Fregean understanding of concepts, to claim that the content of the representations involved in perceptual experiences is of a different (nonconceptual) kind just is to claim that the subject doesn't posses the concepts involved in a psychologically relevant characterization of such content, and, as I argued, the neo-Fregean understanding of concepts is, in turn, independently and plausibly motivated by the need to accommodate the cognitive significance of content. Heck's neo-Fregean account of concepts thus makes his position immune to the state / content confusion that SNC2 allegedly exemplifies and it indeed illustrates how the alleged error becomes a state / content error error.

\section{Icons and reasons.}

Could the sub-personal worry discussed in last section with regard to Fodor's nonconceptualism apply to Heck's (2007) argument for perceptual nonconceptualism? In addressing this question, I turn back again to the third question outlined at the end of Section 2: is the different kind of content that perceptual representations have in virtue of their iconic structure the content of the subject's perceptual experience? The sub-personal worry may strike back for Heck's version of perceptual nonconceptualism because the idea that a subject 
could undergo genuine personal-level perceptual experiences even while her conceptual abilities are switched off sits badly with the broadly Kantian considerations that move, not the advocates of the state / content distinction, but the traditional perceptual conceptualist. And it is not just traditional perceptual conceptualists who may disturb the waters here, some friends of perceptual nonconceptualism (Jacob \& Jeannerod, 2003) also argue that at least one kind of nonconceptual content in visual perception - what they call visuomotor content - does not enter into the subject's conscious visual awareness and hence is not part of the subject's visual experience.

It is precisely in relation to certain instances of (at least pre-theoretically) nonconscious representations that this worry usually arises, as some well known experimental results seem to show a dissociation between the content of visual experiences and the information that guides the subject's fine-grained sensorimotor action based on those experiences - a putative example involves the Titchener circles illusion (Byrne, 2001; Poston, 2007). On one version of this illusion, two circles of the same size are perceived as being different when one is surrounded by an annulus of smaller and the other by an annulus of larger circles. The circle surrounded by smaller circles appears (incorrectly) to be bigger than the other. However, when the illusion is implemented using 3D pieces, and subjects are asked to pick up one of the central circles, their grip accurately corresponds to the actual size of the center disc, instead of being scaled to the illusory size that the disc is experienced as having (Aglioti et al., 1995).

So, here is this version of the sub-personal worry. Cases like the Titchener illusion show that the information that guides the subject's visually guided motor action does not capture how the world appears to the subject. Otherwise, the finger-thumb aperture would have been scaled to the illusory size the circle is perceived as having. Since it is essential that perceptual representations be located at the personal-level, i.e., that they be part of the subject's experience, so that they can enter into true explanations of intentional behavior and since at least some action-oriented representations (like the ones involved in the grasping of Titchener circles) do not seem to be part of the subject's experience, their content cannot be 
considered content of a relevantly different (nonconceptual) kind, i.e., it cannot be considered personal-level nonconceptual content (see e.g. Poston, 2007).

Now, the 3D version of the Titchener circle illusion is usually considered in the empirical literature as supporting Milner and Goodale's $(1995,2006)$ 'dual visual systems hypothesis' (see also Goodale et. al., 1991). According to this view, the mechanisms and coding of information in conscious visual experience are different from, and quite independent of, the mechanisms and coding of information used to guide fine-grained online visuomotor action. The dorsal pathway connects the primary visual cortex (V1) to the posterior parietal cortex - the brain area for motor control — and it provides information for the guidance of skilled visuomotor action. The ventral stream runs from V1 to the inferotemporal cortex - the conceptual and language processing area of the brain. It is considered responsible for the subject's recognitional and classificatory abilities concerning visually guided action. The ventral stream - Milner and Goodale claim — subserves conscious perceptual judgment. In the Titchener illusion, the dissociation between illusory conscious visual content and the fine-grained information that guides motor actions is thus usually explained by reference to this dual stream model.

However, the empirical literature does not unequivocally support this interpretation. It has been suggested, for instance, that there may be rather more interaction between the two streams that the initial experiments seemed to suggest and that the level of such interaction is task-dependent (see e.g. Ellis et al., 1999). The philosophical discussion of the empirical literature regarding this type of illusion has been considerable (see e.g., Clark, 2001 and Jacob \& Jeannerod, 2003), so I will mention it only briefly here. My main concern, to be clear, is whether or not the dissociation between conscious visual content and fine-grained motor-guided behavior observed in some cases of illusory visual perception provides a good reason for supporting the claim that the notion of nonconceptual content that comes out of a version of perceptual nonconceptualism like Heck's (2007) cannot be considered the required (personal-level) content of the subject's perceptual experiences. I don't think it does. To explain why, consider Clark's (2001) analysis of these results. Clark's suggestion for connecting intentional action to conscious visual experience is to make the relationship 
indirect, mediated by the use of other cognitive resources - especially attention — which put sensory systems in contact with higher-level faculties, such as working and episodic memory. If this picture is right, then perception is really geared towards recalling and reasoning and only indirectly towards action. When we say that the content of perceptual experiences (illusory or not) guides our behavior, 'we must unpack that notion of guidance as the high-level, intentional selection of action types and targets - we must depict it as the capacity to consciously use the perceptual array to identify goals, plan actions, and select skilled routines ..., but not to control the fine detail of those sensorimotor routines themselves' (Clark, 2001: 516).

That the grasping of the middle circle is adjusted to their real size, not to their perceived size, would thus imply, according to this view, that the content of the visual representation doesn't control the fine detail of the subject's action. Instead it guides action in a rather mediated way, by selecting the target circle and by choosing a type of action (grasping) to apply to it - both these choices being mediated by the use of higher-level cognitive faculties. In visual perception, the notion of nonconceptual content thus remains relevant for true explanations of intentional behavior once we replace an experience-based control for an experience-based selection model. ${ }^{\mathrm{xi}}$

Interestingly, the hypothesis of experience-based selection (EBS), as Clark labels it, may seem to fit best with conceptualist accounts of the content of perceptual experience, as Clark himself acknowledges (Clark, 2001, pp. 513-514). However, it's Clark's "radical" counter-suggestion for reconciling EBS with the notion of nonconceptual content that I draw on here. The counter-suggestion is radical because it involves the construction of a notion of perceptual content that includes both the traditional, passive, filling out of visual space and the way such experience affords fluent engaged action (Clark, 2001, pp. 514-515. See also Clark, 2009).

It might be suggested, in response, that by thus making the potential deployment of sensorimotor skills — or the 'implicit knowledge of potentials for fine-tuned action', as Clark (2001, p. 515) calls it - into an element of the nonconceptual content of perceptual 
experience, we drive an unacceptable wedge between experience and a subject's reasons for action ${ }^{\mathrm{xii}}$. This is not the case. We need instead to distinguish two ways in which a state can provide a subject with reasons. One way is to provide for some kind of verbal justification of a response. The other, arguably more fundamental way, is to reveal the response to the subject as appropriately grounded in her own experience ${ }^{\text {xiii. }}$. It is in this latter sense that the contents of nonconceptual states may be said to provide reasons for actions. Clark piggybacks here on Dretske's (2006) view that conscious experience can occur alongside a belief that one is aware of nothing, i.e., that we sometimes do not notice the things we are consciously aware of. It would thus not be difficult for him to extend this view to the $3 \mathrm{D}$ case scenario and claim that the subjects are consciously aware of both the illusory and the right size of the circles. It is just that they do not notice the latter. They are consciously aware of it at the sensorimotor level and it is their experience at this level that provides them with a reason, albeit a non-verbal one, for their action. Clark's radical counter-suggestion thus escapes the sub-personal worry by depicting implicit knowledge of potentials for fine-tuned action as also determining, in part, the way things look to the subject ${ }^{\text {xiv }}$.

More important for my purposes, however, is the already mentioned consideration that when we seek to explain intentional behavior, the explanandum is not the complex set of fine adjustments involved in the implementation of such behavior. What we want to explain is gross intentional behavior. It's precisely gross intentional behavior that is at issue in the discussion of the kind of content possessed by the representations involved in cognitive maps. We are, for example, not concerned with the fine details of foot placing or head turning. Although fine-grained sensorimotor action is the focus of the $3 \mathrm{D}$ version of the Titchener circle illusion, most situations where mental representations have an explanatory role to play are situations in which such fine detail is not the target of the explanation. The content of the representations that guide gross intentional behavior seems to belong naturally to the personal-level domain, since the faculties exercised in the guidance of the behavior are high-level, conscious cognitive faculties. 


\section{Conclusion.}

In this paper I have argued that, given a psychologically sensitive notion of content, structural properties of mental states provide good criteria for determining the kind of content those states possess. I have examined this issue in the light of two deceptively similar recent arguments (Fodor, 2007 and Heck, 2007), aiming to show that the iconic structure of perceptual representations establishes their content as content of a different (nonconceptual) kind. I have argued that when such cognitive significance is captured in the syntactic terms that Fodor's understanding of GC demands, the resulting nonconceptualist position is open to a version of what I have called the sub-personal worry, i.e., the worry that it is actually the subject's conceptual repertoire that makes this kind of nonconceptual content available for the subject in experience. Fodor's nonconceptualism thus is a weaker version of the view, for although non-conceptual content can be regarded as content of a different kind, it is not, on this account, content of the right kind. Heck's neo-Fregean understanding of GC, by contrast, not only makes the state-structure to content-nature strategy successful. It helps illustrate how, on a neo-Fregean approach, the state / content error becomes a state / content error error. Heck's neo-Fregean nonconceptualism undermines the state / content dichotomy by relying on a view of concepts and concept possession so essentially tied to cognitive abilities that the logical independence of the theses that characterize the state and the content view of nonconceptualism becomes unsustainable. Finally, I have discussed whether the sub-personal worry still affects Heck's position, as cases of illusory visual experiences like the Titchener illusion seem to show a dissociation between the content of the experience and the information that guides the subject's fine-grained sensorimotor action. I have argued that any such worry disappears once perceptual content is construed on the more explanatorily relevant model of experience-based selection.

I'd like to end with a brief word about the differences between Fodor's and Heck's versions of nonconceptualism. It may seem, from the arguments put forward in this paper, that the neo-Fregean account is preferable, as it doesn't succumb to the subpersonal worry. Yet, it is important to bear in mind that this approach has difficulties of its own. The main problem for the neo-Fregean nonconceptualist is to provide a 
convincing account of perceptual justification given the distinctive commitment to an internalist epistemology that motivates the view, i.e., the commitment to a notion of perceptual justification constrained by the idea that the justification of perceptual beliefs supervenes on facts that the subject is able to know by reflection alone. ${ }^{\mathrm{xv}}$ McDowell (1994) has famously characterized the nonconceptualist model of perceptual justification as a view that falls pray to Sellars' (infamous) Myth of the Given (Sellars, 1963). On the nonconceptualist account, what is epistemically available to a subject as a justifier would seem to be, if McDowell were right, just mythically Given to her, i.e., it would be available to the subject without her exercising the appropriate conceptual cognitive capacities $^{\mathrm{xi}}$. Fodor's epistemic externalism - where perceptual justification is cashed out in terms of facts about reliable empirical connections between a subject's responsive dispositions and the content-bearing constituents of her experience- gives priority, by contrast, not to a normative epistemology, but to empirical psychology and thus may seem to have a more straightforward and, arguably, more plausible answer to this question. On Fodor's view, unconceptualized representations can be considered, pace McDowell, the datum that grounds perceptual beliefs and judgments, and hence the process of conceptualization can be viewed as consisting in subsuming content of one (nonconceptual) kind under content of a different (conceptual) kind. But epistemic externalism also faces a number or serious problems, of which the subject's perspective objection is probably the most relevant in the present context ${ }^{\mathrm{xvii}}$. It may thus very well be that an appropriate treatment of the sub-personal worry becomes crucial in evaluating these two competing epistemological approaches. Clearly, the relevance of the worry goes well beyond the specific issues discussed in this paper. It lies in the way in which it highlights a distinction between two distinct epistemological projects.

\section{Acknowledgements}

I would like to thank Richard Heck and an anonymous referee for helpful comments on earlier drafts. Research for this paper was partially funded by the MICINN, Spanish government under the research project FFI2008-06164-C02-02, the CONSOLIDER 
INGENIO 2010 Program, grant CSD2009-0056, and by the Catalan government via the consolidated research group GRECC, SGR2009-1528.

\footnotetext{
${ }^{\mathrm{i}}$ In what follows, unless otherwise noted, I shall be referring to the (non)conceptualism debate as it appears within this tradition.

ii This is not an exhaustive list. See also Martin (1992) and Heck (2000).

iii Technically speaking perceptual experiences, unlike e.g. beliefs, are not mental states, but conscious mental events or episodes. However, like e.g. beliefs, those mental events have semantically evaluable contents. In the aim of clarity, I'll tend to talk about the content of perceptual states or the content of perceptual representations and would thus ignore this distinction. Nothing in my argument depends on this treatment.

iv Also called 'the absolute' and 'the relative' nonconceptualist thesis (Speaks, 2005).

v Susan Hurley in her (2008) paper speaks of a 'causal-constitutive error error'. This is a small tribute to her.

${ }^{\text {vi }}$ The slogan is an accurate slogan on a neo-Fregean view of concepts. I'll return to this in Section 4.

vii See also Block (2007).

viii On a possible worlds account of content, such as e.g. Stalnaker's (1998), all content becomes non-conceptual, but in a rather uninteresting way.

ix But see Toribio (2008).

${ }^{x}$ Cf. e.g. Peacocke's Principle of Dependence: "There can be nothing more to the nature of a concept than is determined by a correct account of the capacity of a thinker who has mastered the concept to have propositional attitudes to contents containing that concept (a correct account of 'grasping the concept"' (Peacocke, 1992, p. 5)

${ }^{x i}$ Jacob and Jeannerod follow Clark and characterize, not their notion of visuomotor content, but the conscious nonconceptual content of visual perception as content that "is not geared towards the guidance and control of action. Rather, it is geared towards the 'selection' of objects that can be either goals for visually guided actions or food for thought" (2003, p. 16).
} 
xii This certainly seems to be one of the referees' worry.

xiii This second way in which a state can provide a subject with reasons is closely related to what Dretske (2006) calls a 'justifying reason'.

xiv Thanks to Andy Clark for clarifying this point in a personal communication.

${ }^{\mathrm{xv}}$ Where reflection includes introspective awareness of the subject's own mental states, $a$ priori knowledge, and memory of all knowledge thus acquire. Pryor (2001, p. 104) labels this view 'simple internalism'.

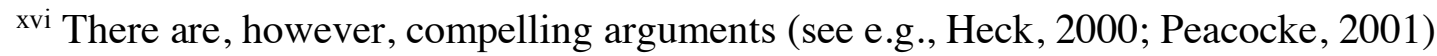

against this allegation, arguments that show that perceptual nonconceptualism is indeed consistent with epistemic internalism.

${ }^{x v i i}$ With thanks to one of the referees for identifying this point so clearly. 


\section{References}

Aglioti, S., Goodale, M. \& J. F. X. DeSouza (1995). Size contrast illusions deceive the eye but not the hand. Current Biology, 5, 679-685.

Bermúdez, J. L. (1998). The paradox of self-consciousness. Cambridge, Massachusetts: The MIT Press.

Bermúdez, J. L. (2003). Thinking without words. New York: Oxford University Press.

Block, N. (2007). Consciousness, accessibility, and the mesh between psychology and neuroscience. Behavioral and Brain Sciences, 30, 481-499.

Brewer, B. (1999). Perception and reason. Oxford: Oxford University Press.

Brewer, B. (2005). Perceptual experience has conceptual content. In E. Sosa \& M. Steup (Eds.), Contemporary debates in epistemology (pp. 217-230). Oxford: Blackwell.

Byrne, A. (2001). Intentionalism defended. The Philosophical Review, 110 (2), 199-240.

Clark, A. (2001). Visual experience and motor action: are the bonds too tight? Philosophical Review, 110 (4), 495-519.

Clark, A. (2009). Perception, action, and experience: unravelling the golden braid. Neuropsychologia, 47 (6), 1460-1468.

Cussins, A. (1992). Content, embodiment and objectivity: The theory of cognitive trails. Mind, 101 (404), 651-688.

Davies, M. (1992). Aunty's own argument for the language of thought. In J. Ezquerro \& J.M. Larrazabal (Eds.), Cognition, semantics and philosophy: Proceedings of the first international colloquium on cognitive science (pp. 235-271). Dordrecht: Kluwer Academic Publishers.

Dretske, F. (2006). Perception without awareness. In T. S. Gendler \& J. Hawthorne (Eds.), Perceptual experience (pp. 147-180). Oxford: Oxford University Press.

Ellis, R., Flanagan, J. \& Lederman, S. (1999). The influence of visual illusions on grasp position. Experimental Brain Research, 125, 109-114.

Fodor, J. (2007). The revenge of the given. In J. Cohen \& B. McLaughlin (Eds.), Contemporary debates in philosophy of mind (pp. 105-116). Malden, MA:

Blackwell.

Fodor, J. (1987). Psychosemantics. Cambridge, MA: MIT Press.

Fodor, J. (2003). Hume variations. Oxford: Oxford University Press. 
Fodor, J. (2004). Having concepts: a brief refutation of the 20th century. Mind \& Language, 19, 29-47.

Fodor, J. \& Pylyshyn, Z. (1988). Connectionism and cognitive architecture: a critical analysis. Cognition, 28 (1), 3-71.

Haffenden, A.M., Schiff, K.C. \& Goodale, M.A. (2001). The dissociation between perception and action in the Ebbinghaus illusion: non-illusory effects of pictorial cues on grasp. Current Biology, 11, 177-181.

Heck, R. (2000). Nonconceptual content and the 'space of reasons'. Philosophical Review, 109 (4), 483-523.

Heck, R. (2007). Are there different kinds of content? In J. Cohen \& B. McLaughlin (Eds.), Contemporary debates in philosophy of mind (pp. 117-138) Malden, MA: Blackwell.

Hurley, S. (2008). Varieties of externalism. In R. Menary (Ed.), The extended mind. Aldershot: Ashgate Press.

Jacob, P. and Jeannerod, M. (2003). Ways of seeing. The scope and limits of visual cognition. Oxford: OUP.

Laurier, D. (2004). Nonconceptual contents vs. nonconceptual states. Grazer Philosophische Studien, 68, 23-43.

Lewis, D. (1970). General semantics. Synthese, 22, 18-67.

Martin, M. G. F. (1992). Perception, concepts, and memory. Philosophical Review, 101 (4), 745-63.

McDowell, J. (1994). Mind and world. Cambridge: Harvard University Press.

Peacocke, C. (1992). A study of concepts. Cambridge, Massachusetts: MIT Press.

Peacocke, C. (2001). Does perception have a nonconceptual content? Journal of Philosophy 98, 239-264.

Poston, T. (2007). Cognitive abilities and the conceptualist/ nonconceptualist debate. American Philosophical Association, Pacific Division Meeting, April 3-8, 2007. Available at http://www.southalabama.edu/philosophy/poston/CognitiveAbilitiesandtheConce ptualistNonconceptualistDebate(LV).doc

Pryor, J. (2001). Highlights of recent epistemology. British Journal for the Philosophy of Science, 52, 95-124.

Sellars, W. (1963). Perception and reality. London: Routledge and Kegan Paul.

Stalnaker, R. (1968). A theory of conditionals. In N. Rescher (Ed.), Studies in logical 
theory (pp. 98-112). Oxford: Basil Blackwell.

Stalnaker, R. (1998). What might nonconceptual content be? In E. Villanueva (Ed.), Concepts (pp. 339-352). Atascadero, CA: Ridgeview Press. Tye, M. (2006). Nonconceptual content, richness, and fineness of grain. In T. Gendler \& J. Hawthorne (Eds.), Perceptual experience (pp. 504-530). Oxford: Oxford University Press.

Toribio, J. (2008). 'State versus content: The unfair trial of perceptual nonconceptualism'. Erkenntnis, 69 (3), 351-361. 